\title{
Phenotypic Analysis of Germination Time of Individual Seeds Affected by Microenvironment and Management Factors for Cohort Research in Plant Factory
}

\author{
Eri Hayashi ${ }^{1,2, *}$, Yumiko Amagai ${ }^{3}$ (D) , Toru Maruo $^{2}$ and Toyoki Kozai ${ }^{1}$ \\ 1 Japan Plant Factory Association, 6-2-1 Kashiwanoha, Kashiwa, Chiba 277-0882, Japan; \\ kozai@faculty.chiba-u.jp \\ 2 Graduate School of Horticulture, Chiba University, 648 Matsudo, Matsudo, Chiba 271-8510, Japan; \\ maruo@faculty.chiba-u.jp \\ 3 Center for Environment, Health and Field Sciences, Chiba University, 6-2-1 Kashiwanoha, Kashiwa, \\ Chiba 277-0882, Japan; amagai@chiba-u.jp \\ * Correspondence: ehayashi@npoplantfactory.org; Tel.: +81-4-7137-8318
}

Received: 30 September 2020; Accepted: 26 October 2020; Published: 29 October 2020

\begin{abstract}
Plant phenotyping plays a crucial role in understanding variations in the phenotype of individual plants affected by environment, management, and genotype. Measurement of seed germination is an important phenotyping stage as germination impacts on the whole plant growth process. However, germination measurement has been limited to germination percentage of a seed population. Understanding of the germination time, from sowing to outbreak of the radicle from seed coat, at a single seed level is essential. How individual germination time and further plant growth are affected by its microenvironment and management factors remains elusive. Plant phenotype measurement system was developed to assess individual germination time of romaine lettuce (Lactuca sativa L. var. longifolia), using time-series two-dimensional camera images, and to analyze how microenvironment (volumetric water percent in seed tray, individual seed surface temperature and air temperature) and management factors (coated/uncoated seeds) affect the germination time for plant cohort research, emphasizing practicality in commercial cultivation. Germination experiments were conducted to demonstrate the performance of the system and its applicability for a whole plant growth process in a plant factory for commercial production and/or breeding. The developed phenotyping platform revealed the effects of microenvironment and management factors on germination time of individual seeds.
\end{abstract}

Keywords: germination time; phenotyping; microenvironment; management; plant cohort research; plant factory with artificial lighting (PFAL); productivity

\section{Introduction}

Understanding how microenvironment and management factors affect variations in germination time of individual seeds is an important step towards robust and consistent agricultural productions. Variations in the traits (i.e., phenotypes) of individual plants are attributable to mainly three factors: environment, genotype (specific to species and cultivar), and management (human and/or machine intervention), including seed treatments. Plant phenotyping plays a crucial role in understanding these interactions [1,2]. Plant phenotyping is a set of methodologies and protocols used to study plant growth, performance, architecture, and composition at different scales of organization, from organs to canopies, and it reveals the plant trait dynamics in a non-invasive and non-destructive manner [1-4]. 
These measured traits may display macro- and micro-environmental variations [5]. Over the past years, the focus has been put on developing high-throughput accurate and rapid phenotyping systems together with image processing algorithms, which possesses potential to be adapted also for the study under controlled environmental conditions $[1,6,7]$.

Plant factory with artificial lighting (PFAL) is a closed plant production system, with an almost airtight and well-insulated structure, which allows increased resource utilization efficiency under a precisely controlled environment to produce high quantities of high quality plants year-round, completely independently of outdoor conditions [8-14]. However, despite the highly controlled environment in PFAL, the variations in plant individuals have been found specifically at the time of harvesting, urging the development of a new phenotypic analysis platform [2,15].

Seed germination is one of the most important initial stages of plant growth, and the ecophysiological status of germinated seeds has an impact on the subsequent plant growth process $[2,16]$. Germination is generally defined as emergence of the radicle through the surrounding structure after water uptake by the seed $[17,18]$. Germination time from sowing to outbreak of the radicle from seed coat (germination time hereafter) and its uniformity of seeds are essential for plant growth, as they consequently affect the productivity of plant production. Plant seeds have complex phenotypes that are difficult to quantitatively assess [19]. Therefore, measurement of seed germination is one of the important initial stages of plant phenotyping.

Measurement of seed germination has gained much attention from plant growers, seed scientists, and other plant biologists. Seeds from different individual plants, populations, seed lots and treatments all influence germination percentages, speed, and uniformity [16]. Germination time provides valuable information about the favorability of germination conditions [18]. In order to achieve uniform harvests, it is important to identify the causes of the variations in seed germination time and eliminate those factors that contribute to the variability [2]. The time course curves produced in seed germination tests provide considerable information about germination time and its uniformity of seeds [17].

However, measurement of seed germination has been limited to the germination percentage over a population of seeds that have completed germination at a given time, but not the germination time of an individual seed [17]. Indeed, the outputs of various measurement methods of seed germination that have been adopted for many years have been a mean or median of germination time or percentage of specific seed lots. The past studies have indicated the limitations of these methods $[16,17,20,21]$. To achieve accurate quantification of germination, there have been studies including high-throughput automatic scoring and evaluation of germination [22,23]. However, how microenvironment and management factors affect germination time of individual seeds and subsequent plant growth has not been investigated in detail. In order to elucidate the individual phenotype variations, it is essential to measure germination time of individual seeds and to analyze how microenvironment and management factors affect individual germination time and subsequent plant growth.

In this study, a plant phenotype measurement system was developed to assess germination time (GT) of individual seeds of romaine lettuce (Lactuca sativa L. var. longifolia) in seed trays each with 300 seeds, using time series data on two-dimensional (2D) camera images, and to analyze each germination time as affected by its surrounding microenvironment (volumetric water percent of the substrate in each tray, individual seed surface temperature and air temperature) and management factors (coated and uncoated seeds) of individual seeds. Using this system, plant cohort research was conducted in this study as an initial stage of the whole plant growth process. The modular system was designed with an emphasis on practicality and scalability in commercial plant production in PFALs. This system achieves low cost with small cameras and sensors, along with cultivation method similar to the one in commercial PFALs. Experiments on germination were conducted to demonstrate the performance of the system and its applicability for a whole plant growth process in a PFAL for large-scale commercial production and/or breeding. This present study is part of and will contribute to a broader plant cohort research project. 
In the plant cohort research, the life cycle phenome history of individual plants can be measured continuously and noninvasively, and analyzed from seed sowing to harvesting by using phenotyping units, along with the time course data on environment, management, and resource inputs/outputs in PFAL $[2,11,12,24]$. Plant cohort refers to a relatively large group of plant individuals with a statistical factor (such as cultivar, planting density, and cultivation system) in common with the plants in a PFAL for commercial plant production and/or breeding $[2,11,12,24]$. For the plant cohort research, the time series data sets in the data warehouse (DWH) can be used, which leads to identification of an optimal set points of environmental factors for maximizing multi-objective function, and concurrently improve plant productivity and breed new cultivars in PFAL [2,11,12,24].

Through this study, germination time of individual seeds were obtained from time series 2D camera images by using the developed plant phenotype measurement system as an initial stage of the plant cohort research in PFALs. Furthermore, the phenotyping platform revealed the effects of microenvironment and management factors on germination time of individual seeds.

\section{Materials and Methods}

\subsection{Description of the System}

A germination container box (GCB) equipped with phenotyping and microenvironmental sensing units was designed and developed (Figure 1). GCB consists of five major units and parts: temperature control $(A-C)$, phenotyping $(D-G)$, sensors $(H)$, cultivation (I-K), and an exterior box frame (L) (Figure 1a). The original GCB (WR-60CHL-S; Keibunsha Seisakusho, Hiroshima, Japan) was composed of an air conditioner, air outlet of air conditioner, and electric heater, which were built in an exterior box with frame (A, B, C, and L, respectively; Figure 1a,b).

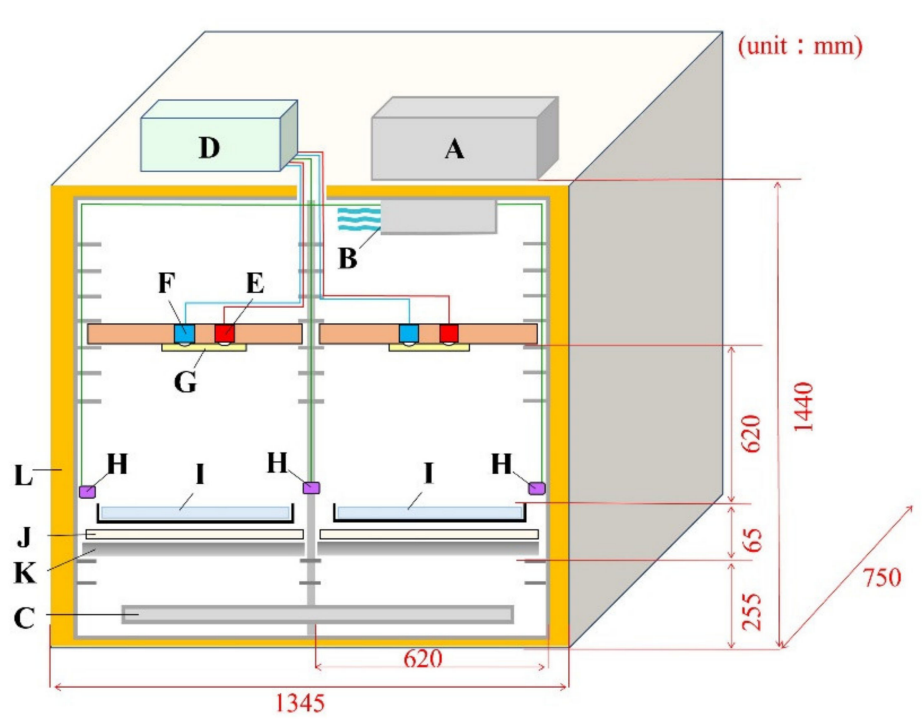

(a)

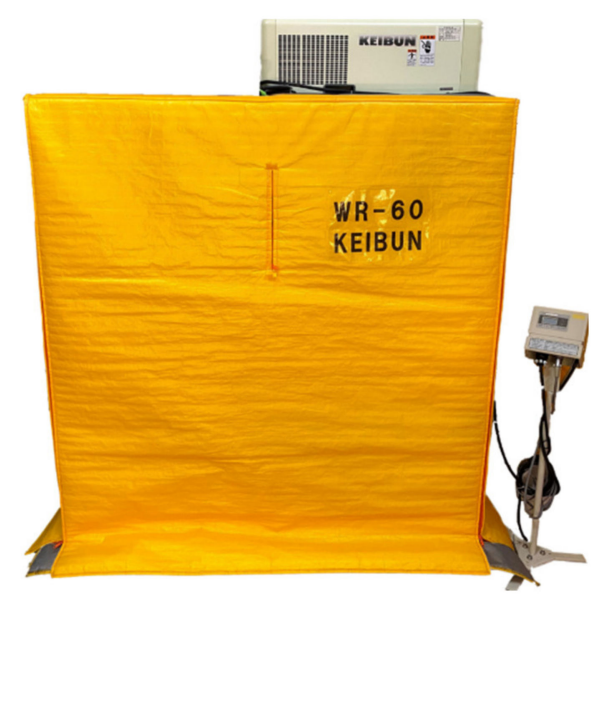

(b)

Figure 1. Cont. 


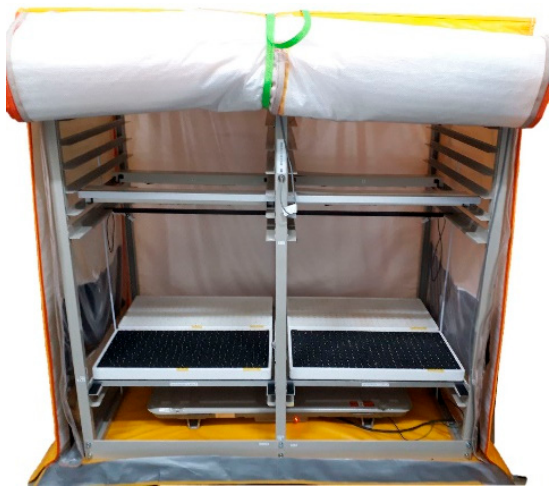

(c)
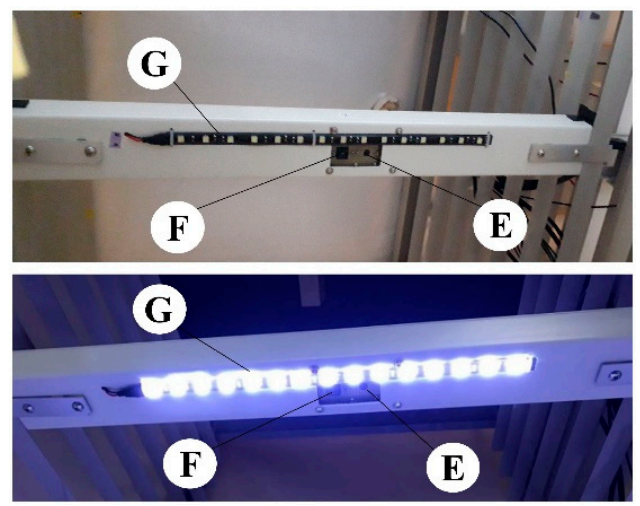

(d)

Figure 1. Germination container box (GCB) equipped with phenotyping and microenvironmental sensing units. (a) Schematic diagram. (1) Temperature control unit: Air conditioner (A), Air outlet of air conditioner (B), Electric heater (C). (2) Phenotyping unit: Control board $(\times 4)(\mathrm{D})$, Red-green-blue $($ RGB) camera $(\times 4)($ E), Thermal camera $(\times 4)($ F), White light emitting diode $($ LED) for flash $(\times 4)(G)$. (3) Air temperature/relative humidity sensor $(\times 4)(\mathbf{H})$. (4) Cultivation unit: Seed tray with substrate (seed tray) ( $\times 4)(\mathbf{I})$, Acrylic plate (J), Reinforcement bar (K). (5) Exterior box with frame (L); (b) Exterior of GCB; (c) Inside view of GCB; (d) Phenotyping unit with the flash off (upper image) and on (lower image).

Phenotyping and microenvironmental sensing and cultivation units were additionally installed to GCB; newly installed items include a control board (Raspberry Pi 3 Model B; Raspberry Pi Foundation, Cambridge, United Kingdom) $(\times 4)$, red-green-blue (RGB) camera (Raspberry Pi Pi NoIR Camera Module V2; Raspberry Pi Foundation, Cambridge, United Kingdom) $(\times 4)$, thermal camera (FLIR Lepton 3.5; FLIR Systems, Inc., Wilsonville, OR, USA) $(\times 4)$, white light emitting diode (LED) for flash of RGB camera (15 white LED tape, 300 mm) (SOF-15W-30-3SMD; Tokulumi Co., Ltd., Kwai Chung, Hong Kong) ( $\times 4$ ), air temperature/relative humidity sensor (AM2302; Guangzhou Aosong Electronics Co., Ltd., Guangzhou, China) $(\times 4)$, seed tray with substrate (seed tray) $(605 \times 300 \times 42 \mathrm{~mm})(\times 4)$, acrylic plate (thickness: $3 \mathrm{~mm}$ ), and reinforcement bar (thickness: $20 \mathrm{~mm}$ ) (D, E, F, G, H, I, J, K; Figure 1a).

The phenotyping units, sets of RGB camera, thermal camera $(160 \times 120$ pixel, with temperature measurement function), and LED were installed $620 \mathrm{~mm}$ above the surface of each seed tray (Figure 1c,d). As emphasizing the design principle for the phenotyping unit, cost-effectiveness and compactness were given priority for the selection of the cameras, with a vision to ultimately apply to commercial production in PFALs and breeding. Air temperature/relative humidity sensors were setup in the upper right/left of the cultivation trays. The cultivation unit contains space for four seed trays, designed to maintain consistency of each tray's location. Each substrate in the seed tray consists of $300(=25 \times 12)$ foamed urethane cubes, each with a hole of $11.5 \mathrm{~mm}$ in diameter and $6 \mathrm{~mm}$ in depth. All seeds in each tray are numbered in accordance with the position in the seed tray $\left(\mathrm{P}_{i}(i=1 \sim 300)\right)$ (Figure 2). By using the air conditioner and electric heater built in the GCB, air temperature inside the GCB can be controlled within the range of 10 to $40{ }^{\circ} \mathrm{C}$. 


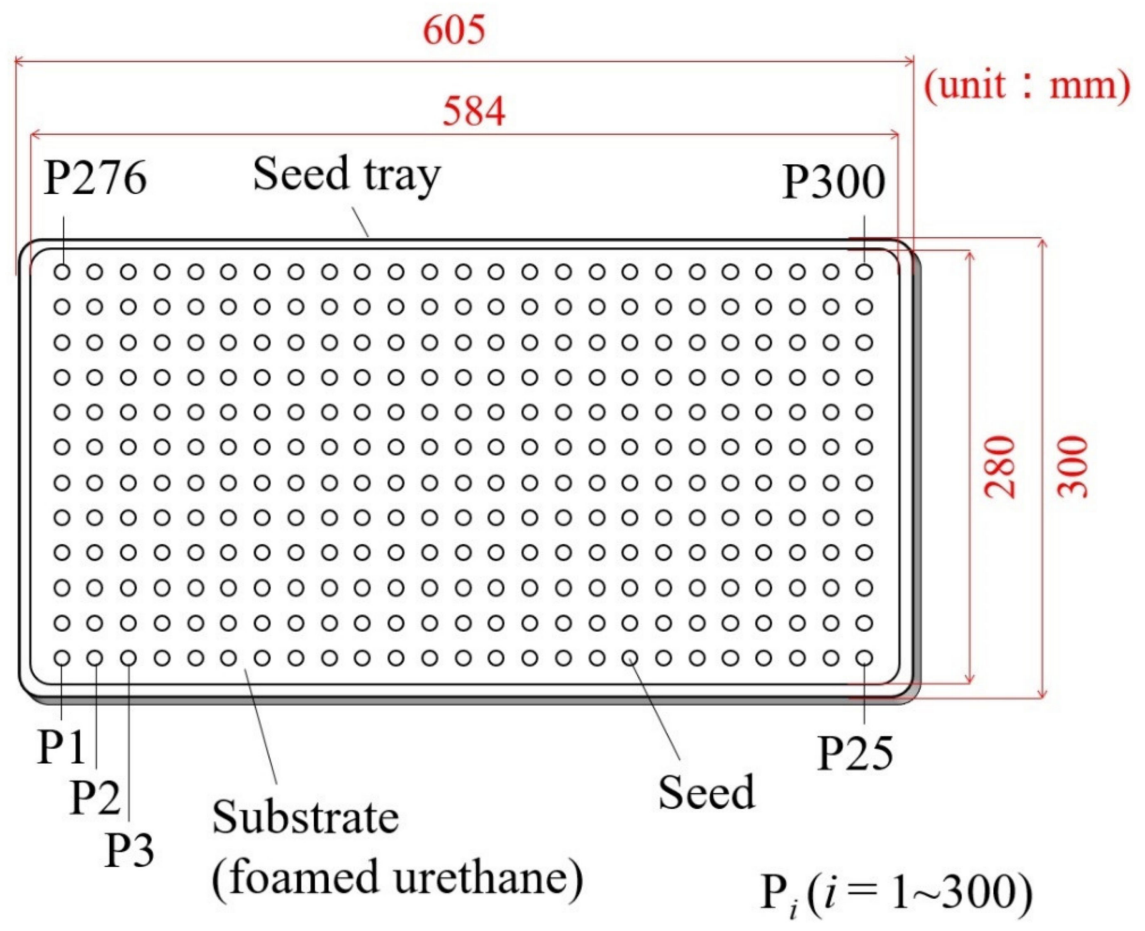

Figure 2. Plane view of seed tray with substrate consisting of $300(=25 \times 12)$ foamed urethane cubes. All seeds in each tray are numbered in accordance with the position in the seed tray with plant seed number $\left(\mathrm{P}_{\mathrm{i}}(\mathrm{i}=1 \sim 300)\right)$.

\subsection{Phenotyping and Microenvironmental Sensing Units}

For unification and analysis of time series data, a DWH was built [25] and further modified to improve operability. Each RGB camera, thermal camera, LED, and air temperature/relative humidity sensor (phenotyping and microenvironmental sensing unit) is connected to each control board and designed to be activated at specified time intervals (the shortest possible period of every one minute). All data obtained from phenotyping and microenvironmental sensing units are automatically sent to the DWH through the control boards.

To derive GT of individual seeds, the RGB camera was used to acquire time series 2D image data. The thermal camera was applied to obtain time series data of seed surface temperature of individual seeds (SST). Prior to installing thermal cameras, calibration was performed using thermocouples. With the thermal camera, 19,200 pixels/surface temperatures of substrate per image are acquired. The system was programmed to extract SST (300 pixels per image/seed tray) automatically from the original thermal image. All SST data are assigned with consecutive seed numbers in the seed tray $\left(\mathrm{P}_{i}(i=1 \sim 300)\right)$ (Figure 2).

\subsection{Germination Time (GT) Acquired from RGB Image}

GT of individual seeds were acquired from time series RGB images. Figure 3 shows the process of deriving GT from RGB images. Representative images with $0.5 \mathrm{~h}$ intervals are shown. The time series RGB images of seed trays were continuously obtained from the RGB camera at set intervals and then sent automatically to the DWH (Figure 3). One RGB image covers one seed tray that contains 300 seeds on a foamed urethan substrate (Figure 3). Each RGB image of seed tray is processed to be divided into 300 images of individual seeds. Then, these time series RGB images of each individual seed are re-sequenced in a chronological order (Figure 3). 


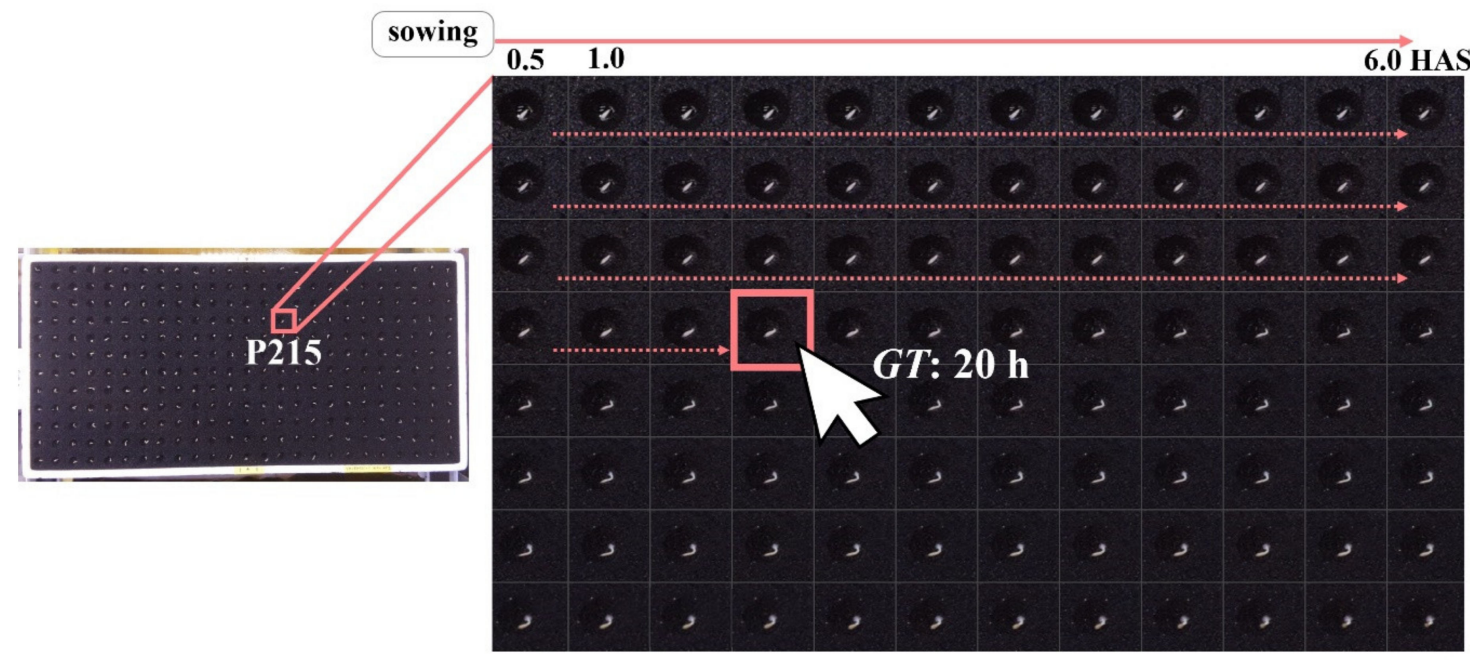

Figure 3. Process of acquiring germination time (GT) from time series red-green-blue (RGB) image data. Time series RGB images of seed trays were obtained from the RGB camera at set intervals and then sent automatically to the data warehouse (DWH) (left image). Each RGB image covers one seed tray with 300 seeds on a foamed urethan substrate (left image). An example of marked seed number P215 is shown (left image). After each RGB image of seed tray is segmented into 300 images of individual seeds, time series of individual seed images are re-sequenced in a chronological order to determine GT by selecting the germinated seed (right image). Time course RGB data of seed P215 every $0.5 \mathrm{~h}$ (HAS: hours after sowing) with GT of $20 \mathrm{~h}$ is shown (right image).

To determine GT, the RGB image of a germinated seed was selected among the time course images of each seed (Figure 3). Binary judgement was made to all the RGB images to identify the presence $(\mathrm{T})$ or absence $(\mathrm{F})$ of germination, i.e., annotation. The decision criteria for the presence of germination were set as when approximately 1-mm-long root/radicle, extending from the outer seed coat or cracked coating, was observed. In addition to determining germination by RGB images, ground truth measurements from all actual seeds at $48 \mathrm{~h}$ after sowing (HAS), hours of imbibition/water absorption, were conducted to confirm or correct the original binary classification/annotation. The GT and binary classification/annotation data together with RGB image data were output to CSV files as data sets along with environment and management data.

\subsection{Experimental Design}

\subsubsection{Data Acquisition}

To demonstrate the performance of GCB with phenotyping and microenvironmental sensing units, experiments were conducted from seed sowing to 48 HAS (germination stage). For this experiment, the actuation time of the RGB camera, air temperature/relative humidity sensor and thermal camera were set at every $0.5 \mathrm{~h}, 0.17 \mathrm{~h}(10 \mathrm{~min})$, and $48 \mathrm{~h}$, respectively.

During the single germination stage, 96 RGB images $(0.5 \mathrm{~h} \times 48 \mathrm{~h})$ per seed tray were obtained by each RGB camera. Twenty-eight thousand and eight hundred data sets with RGB images (300 seeds/seed tray $\times 96$ RGB images), together with annotation data, GT of 300 seeds, and microenvironment and management data can be obtained from the single seed tray from one germination experiment. If four seed trays were used at once in GCB, 115,200 data sets $(28,800 \times 4$ seed trays) can be obtained from a single experiment.

\subsubsection{Variables and Symbols}

List of symbols and variable names are described in Table 1. Besides GT and SST, average GT per 300 seeds in a seed tray $(\overline{G T})$, and average SST per 300 seeds in a seed tray 48 HAS $(\overline{S S T})$ were 
calculated, respectively. Volumetric percentage of nutrient solution in seed tray (VPNS) was quantified, but not for each substrate for individual seeds in this study. Setpoint air temperature of GCB (SAT), air temperature inside the GCB $(A T)$ and average $A T$ at $48 \mathrm{HAS}(\overline{A T})$ were also collected. The germination percentage $(G P)$ was calculated by the number of germinated seeds per 300 seeds in a seed tray 48 HAS. Furthermore, hourly germination rate (speed of germination) (GR) and average GR per 300 seeds in a seed tray 48 HAS $(\overline{G R}=G P / \overline{G T})$ were determined. For the data analysis of experimental results, software R, a language and environment for statistical computing and graphics, was used [26].

Table 1. List of symbols, variable names with descriptions and units.

\begin{tabular}{|c|c|c|}
\hline Symbol & Variable name/Description & Unit \\
\hline$A T$ & Air temperature inside the germination container box (GCB) & \\
\hline$\overline{A T}$ & Average $A T$ at $48 \mathrm{~h}$ after sowing (HAS) & ${ }^{\circ} \mathrm{C}$ \\
\hline C & Coated seed & - \\
\hline$G P$ & Germination percentage per 300 seeds 48 HAS & $\%$ \\
\hline GR & Hourly germination rate of individual seed (inverse of GT) & $\mathrm{h}^{-1}$ \\
\hline$\overline{G R}$ & Average $G R$ per 300 seeds $(G P$ divided by $\overline{G T})$ & $\% \mathrm{~h}^{-1}$ \\
\hline GT & $\begin{array}{c}\text { Germination time course (from seed sowing to outbreak of the radicle from seed coat) of } \\
\text { individual seed }\end{array}$ & $\mathrm{h}$ \\
\hline$\overline{G T}$ & Average GT per 300 seeds & \\
\hline SST & Seed surface temperature of individual seed & ${ }^{\circ} \mathrm{C}$ \\
\hline$\overline{S S T}$ & Average SST per 300 seeds 48 HAS & $c$ \\
\hline$S A T$ & Setpoint air temperature of GCB & ${ }^{\circ} \mathrm{C}$ \\
\hline $\mathrm{U}$ & Uncoated seed & - \\
\hline VPNS & Volumetric percentage of nutrient solution in seed tray & $\%$ \\
\hline
\end{tabular}

\subsubsection{Plant Material and Culture Conditions}

To analyze GT as effected by its surrounding microenvironment and management factors, experiments on seed germination were carried out with a focus on altering air temperature (SAT) and volumetric water/nutrient solution percent in seed tray (VPNS), considering the two major elements for germination to occur: temperature and water $[17,20]$. Thus, as shown in Table 2, two kinds of experiments, altering either (1) SAT or (2) VPNS during the germination stage, were conducted: (1) $S A T$ of $12{ }^{\circ} \mathrm{C}, 16{ }^{\circ} \mathrm{C}, 20^{\circ} \mathrm{C}, 24{ }^{\circ} \mathrm{C}, 28{ }^{\circ} \mathrm{C}, 32{ }^{\circ} \mathrm{C}, 36^{\circ} \mathrm{C}$, and $40{ }^{\circ} \mathrm{C}$, whereas VPNS was fixed at $86 \%$, with management factors of uncoated seed (U) and coated seed (C), i.e., 16 conditions, and (2) VPNS of 77\%, $82 \%$ and $86 \%$ as $S A T$ was fixed at $20^{\circ} \mathrm{C}$ [27] for both $\mathrm{U}$ and C, i.e., 6 conditions.

Table 2. Experimental design (see Table 1 for abbreviations).

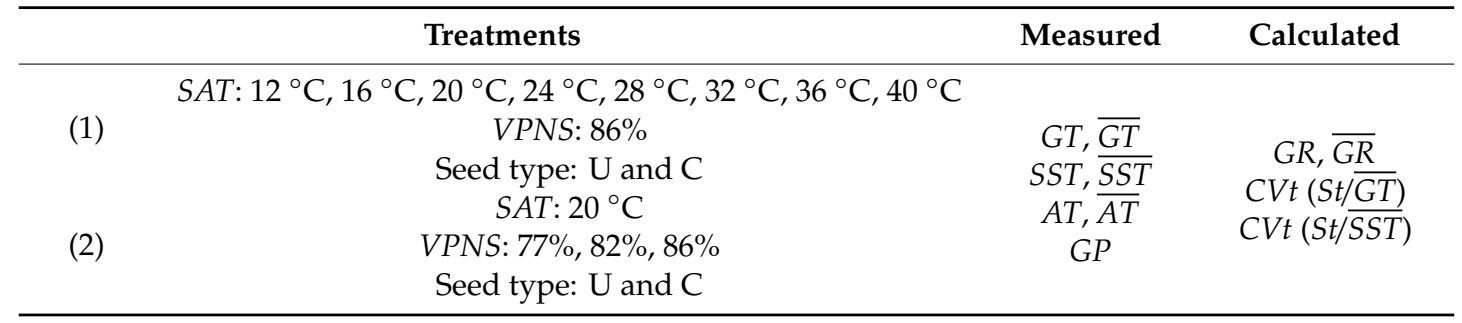

As for management factors, two types of seeds ( $\mathrm{U}$ and $\mathrm{C}$ ) of romaine lettuce (Lactuca sativa L. var. longifolia, Lomaria, TLE487, offered by Takii \& Co., Kyoto, Japan) were used. Substrates with color of black, made of flexible polyurethane foam (MIRAI Co., Ltd., Kashiwa, Japan, $584 \times 280 \times 28$ mm, 300 wells, $12 \mathrm{~mm}$ in diameter $\times 6 \mathrm{~mm}$ deep), were used in the seed trays. For this study, black substrate, instead of white substrate, was chosen to facilitate an accurate detection of GT from RGB images.

For nutrient solution, Chiba University's lettuce formula [28] was used, with nutrient solution temperature, $\mathrm{pH}$ and electrical conductivity of $20^{\circ} \mathrm{C}, 6.5$ and $1.9 \mathrm{mS} \mathrm{cm}^{-1}$, respectively. In addition 
to automated data acquisition with phenotyping and microenvironmental sensing units and other environmental data, management data, such as culturist, time required for sowing, and identified numbers of germinated seeds from RGB images, were collected, along with seed type ( $U$ and C). The experiments were conducted under identical conditions: substrates were soaked in the set amount of nutrient solution and the same GCB was used.

Except when the flashes for RGB camera were on (10 s/time for photographing), inside the GCB was kept dark during the experiment: the photosynthetic photon flux density (PPFD) at the position of the seed tray was 0.03 to $0.05 \mu \mathrm{mol} \mathrm{m} \mathrm{m}^{-2} \mathrm{~s}^{-1}$. The GCB was placed inside the environmentally controllable cultivation room of PFAL, located at Kashiwanoha Campus of Chiba University, with air temperature, relative humidity and $\mathrm{CO}_{2}$ concentrations inside the cultivation room of $20{ }^{\circ} \mathrm{C}, 80 \sim 100 \%$ and $1500 \mu \mathrm{mol} \mathrm{mol}^{-1}$, respectively.

\section{Results}

A plant phenotype measurement system was developed to assess GT of romaine lettuce (L. sativa L. var. longifolia) in seed trays each with 300 seeds, using time series data on 2D camera images, and to analyze each GT as affected by its surrounding microenvironment (SST, VPNS, and air temperature) and management ( $U$ and $C$ ) factors of individual seeds for plant cohort research. Experiments on germination were conducted to demonstrate the performance of the system and its applicability for a whole plant growth process in a PFAL for large-scale commercial production and/or breeding.

GT of individual seeds were acquired from time series RGB images (Figure 4). Figure 3 shows the process of deriving GT from RGB images. Representative images with $0.5 \mathrm{~h}$ intervals are shown. The time series RGB images of seed trays were continuously obtained from the RGB camera at set intervals and then sent automatically to the DWH (Figure 3). One RGB image covered one seed tray that contained 300 seeds on a foamed urethan substrate (Figure 3). Each RGB image of seed tray was processed to be divided into 300 images of individual seeds. Then, these time series RGB images of each individual seed were re-sequenced in a chronological order (Figure 3).

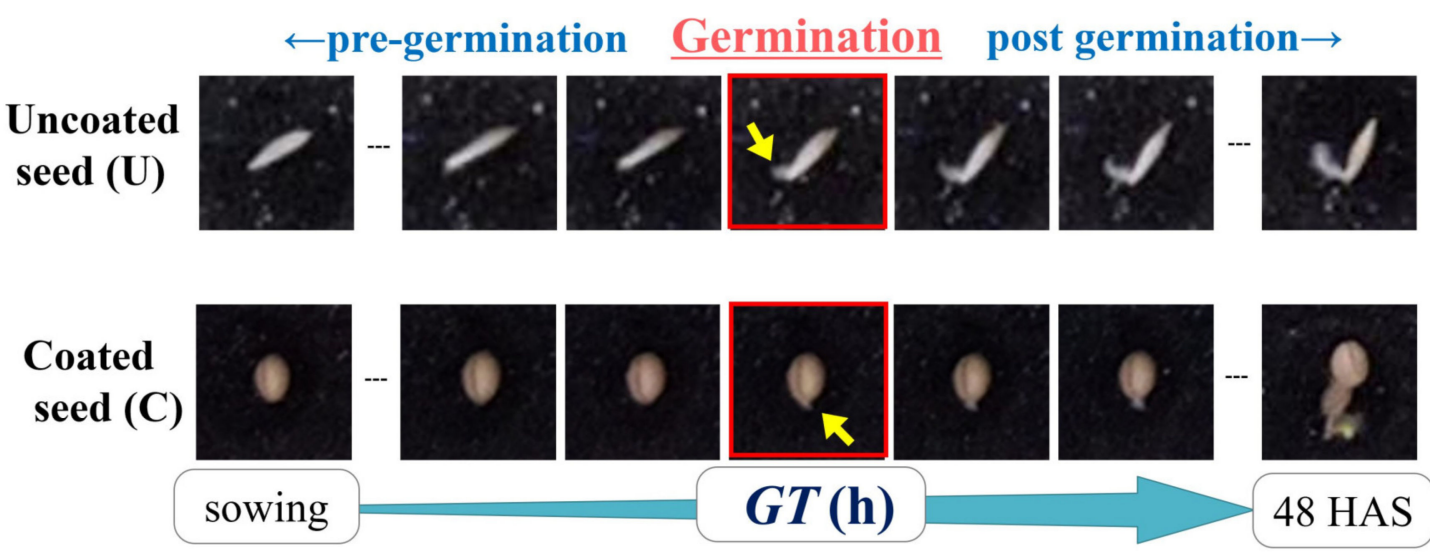

Figure 4. Germination time (GT) acquired from time series red-green-blue (RGB) images, obtained continuously from sowing until $48 \mathrm{~h}$ after sowing (HAS).

To determine GT, the RGB image of a germinated seed was selected among the time course images of each seed (Figure 3). Binary judgement was made to all the RGB images to identify the presence $(\mathrm{T})$ or absence $(\mathrm{F})$ of germination, i.e., annotation. The decision criteria for the presence of germination were set as when approximately 1-mm-long root/radicle, extending from the outer seed coat or cracked coating, was observed. In addition to determining germination by RGB images, ground truth measurements from all actual seeds at 48 HAS were conducted to confirm or correct the original binary classification/annotation. The GT and binary classification/annotation data together with RGB image data were output to CSV files as data sets along with environment and management data. 
In addition to deriving GT of individual seeds from time series RGB camera, the thermal camera was applied to obtain time series data of seed surface temperature of individual seeds (SST). With the thermal camera, 19,200 pixels/surface temperatures of substrate per image were acquired. The system was programmed to extract SST (300 pixels per image/seed tray) automatically from the original thermal image. All SST data were assigned with consecutive seed numbers in the seed tray $\left(\mathrm{P}_{i}(i=1 \sim 300)\right)$ (Figure 2).

Two kinds of experiments, either different (1) SAT or (2) VPNS during the germination stage for both $U$ and $C$, were conducted. For the first experiment, different $S A T$ every $4{ }^{\circ} \mathrm{C}$ from 12 to $40{ }^{\circ} \mathrm{C}$ with VPNS of $86 \%$ was identified; for the second experiment, VPNS of $77 \%, 82 \%$, and $86 \%$ with $S A T$ of $20{ }^{\circ} \mathrm{C}$ was identified (Table 2 ).

Figure 5 shows the probability density function (PDF) of GT to (1) different SAT with VPNS of $86 \%$ (Figure 5a,b) and (2) different VPNS with SAT of $20^{\circ} \mathrm{C}$ (Figure 5c,d), using 300 seeds of U and C, respectively. Variance of GT was found for both $U$ and $C$ in accordance with variable microenvironments, $S A T$ and VPNS, and management factors (Figure 5). Earlier and uniform germination are beneficial for the consistent production. For this experiment, SAT of $24{ }^{\circ} \mathrm{C}$ with $V P N S$ of $86 \%$ and management factor $U$ showed the earliest and most uniform germination (Figure $5 \mathrm{a}$ ).

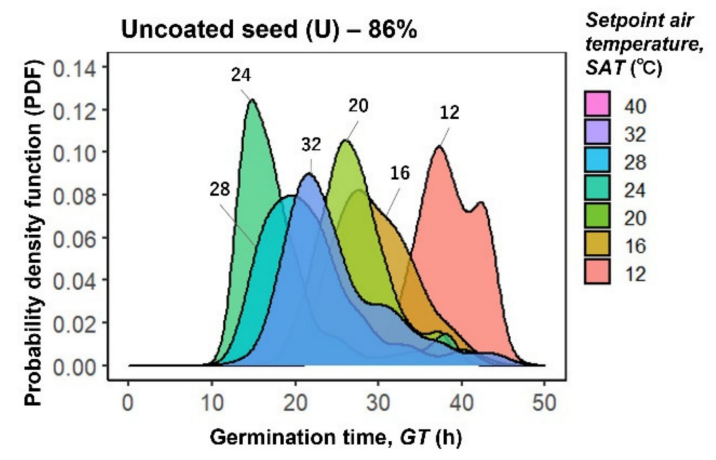

(a)

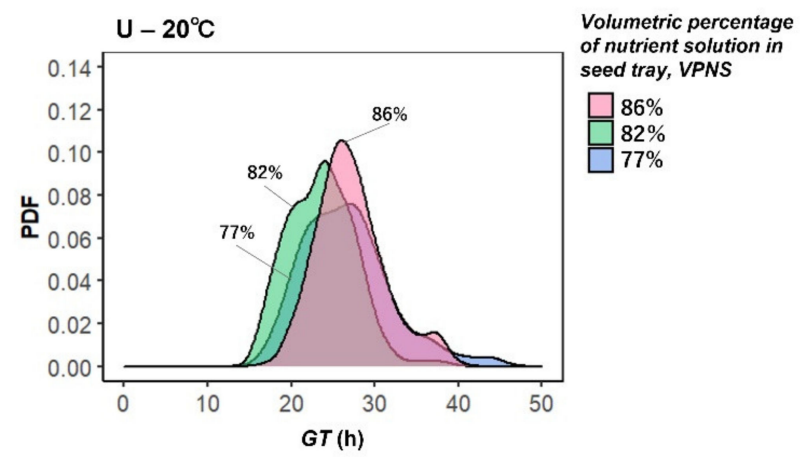

(c)

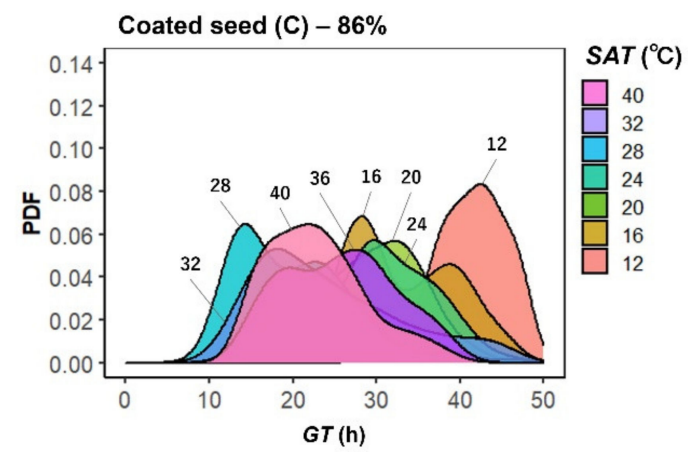

(b)

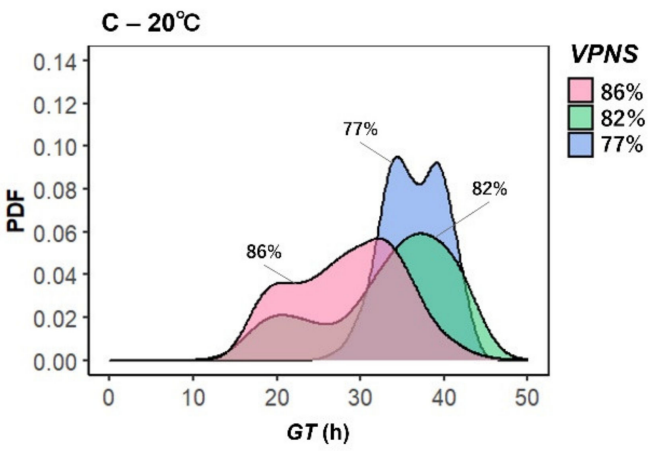

(d)

Figure 5. Probability density function (PDF) of germination time (GT) under (1) different setpoint air temperature (SAT) and volumetric percentage of nutrient solution in seed tray (VPNS) of $86 \%$ each with (a) uncoated seed-U and (b) coated seed-C, and (2) different VPNS and SAT of $20^{\circ} \mathrm{C}$ with $\mathrm{U}$ (c) and C (d) (see Table 1 for abbreviations). 
Figure 6 illustrates scatter diagrams of GT and SST under (1) different SAT with VPNS of 86\% (Figure $6 \mathrm{a}, \mathrm{b}$ ) and (2) different $V P N S$ with $S A T$ of $20^{\circ} \mathrm{C}$ (Figure $6 \mathrm{c}, \mathrm{d}$ ), each with both 300 of $\mathrm{U}$ and C. GT and SST of individual seeds were quantified in response to different SAT, VPNS and U/C (Figure 6). Variance of GT and SST differed depending on the microenvironment and management factor. In this experiment, for $\mathrm{U}$ with different $S A T$ with fixed VPNS, overall germination was limited or not found with $S A T$ of $36^{\circ} \mathrm{C}$ and $40^{\circ} \mathrm{C}$ (Figure 6a, Table 3).

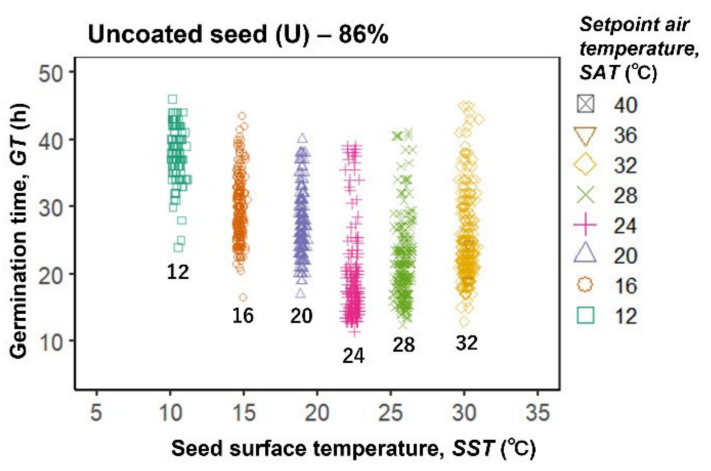

(a)

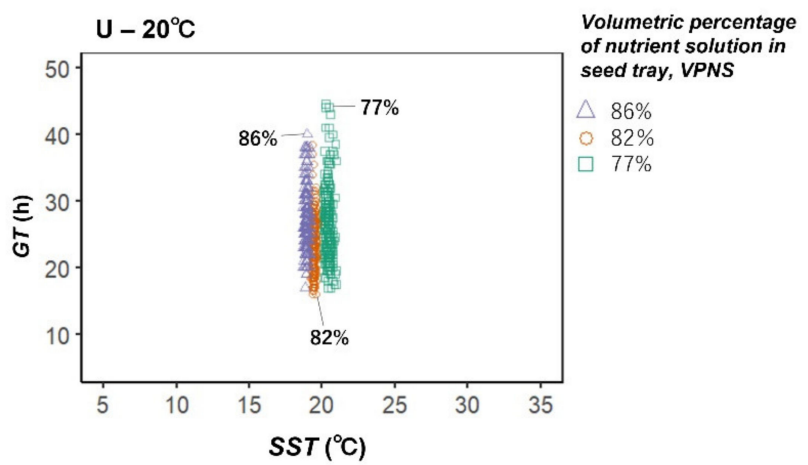

(c)

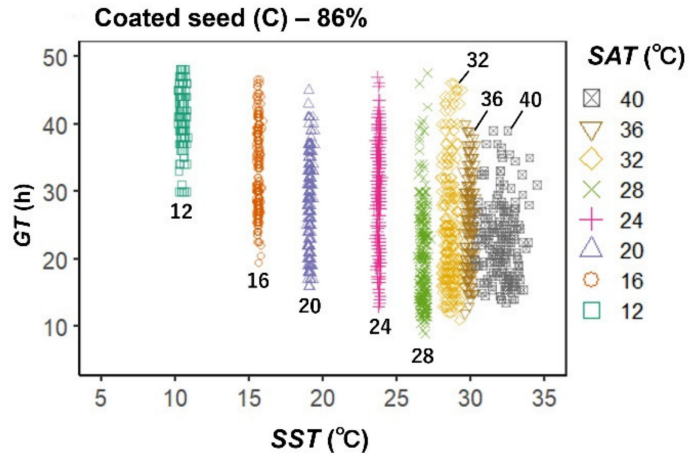

(b)

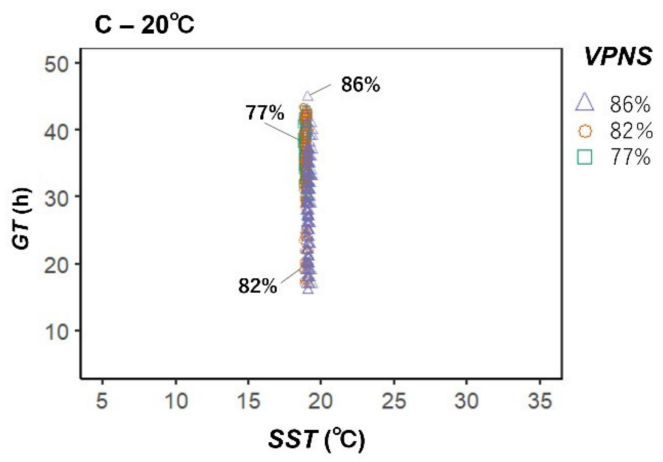

(d)

Figure 6. Scatter diagram of germination time (GT) and seed surface temperature (SST) under (1) different setpoint air temperature $(S A T)$ and volumetric percentage of nutrient solution in seed tray (VPNS) of $86 \%$ each with 300 (a) uncoated seeds- $\mathrm{U}$ and (b) coated seeds-C, (2) different VPNS and $S A T$ of $20^{\circ} \mathrm{C}$ with $\mathrm{U}$ (c) and C (d). Each symbol corresponds to one seed (see Table 1 for abbreviations).

Figure 7 describes $\overline{S S T}$ and $\overline{A T}$ under different $S A T\left(12,16,20,24,28,32,36,40^{\circ} \mathrm{C}\right)$ with VPNS of $86 \%$, each with 300 of both $U$ and C. For both $U$ and $C, \overline{S S T}$ was lower than SAT at higher SAT, especially of $36^{\circ} \mathrm{C}$ and $40^{\circ} \mathrm{C}$, whereas $\overline{A T}$ remained closer to $S A T$.

Table 3 shows $\overline{G T}, \overline{A T}, \overline{S S T}, \mathrm{GP}, \overline{\mathrm{GR}}$, Identified percent, coefficient of variation of GT (CVt) and SST (CVs), each with different VPNS, SAT, and U/C. In addition to $\overline{G T}, \overline{S S T}$ and $\overline{A T}$, GP was measured for each treatment. Identified percent is the percentage obtained by dividing the number of seeds of identified GT from RGB images by germinated seeds 48 HAS. The degree of uniformity of both GT and $S S T$ was quantified with $C V t$ and $C V s$, respectively. Furthermore, $\overline{G R}$ was calculated and indicated the difference in average germination rate for each condition.

$$
S t=\sqrt{\frac{1}{n} \sum_{i=1}^{n}(G T-\overline{G T})^{2}} .
$$




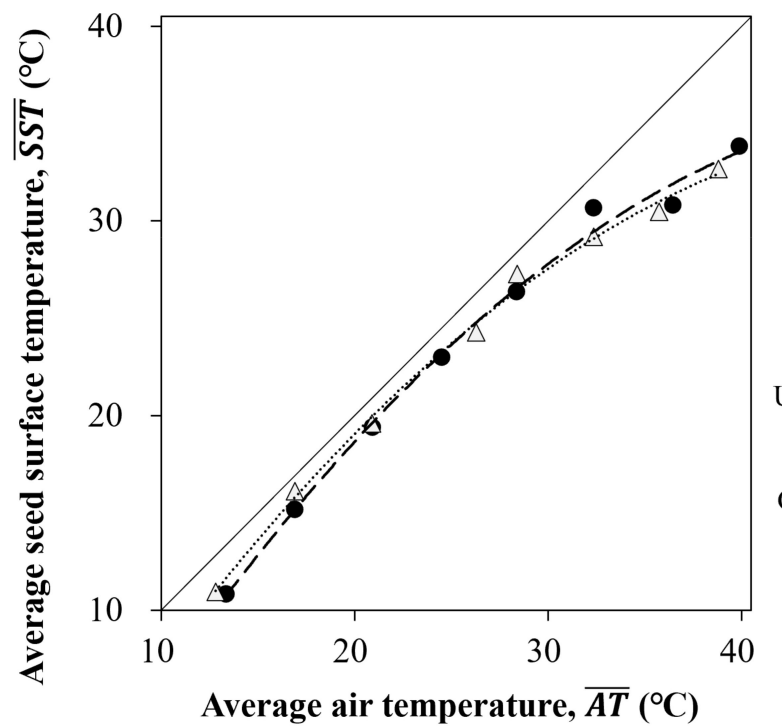

- Uncoated seeds, U

$\triangle$ Coated seeds, C

- - Polynomial (U)

.......... Polynomial (C)

Linear $(S S T=A T)$

$\mathrm{U}: \mathrm{y}=-0.0167 \times A T^{2}+1.73 \times A T$ $\mathrm{R}^{2}=0.994$

$\mathrm{C}: \mathrm{y}=-0.0158 \times A T^{2}+1.63 \times A T$ $\mathrm{R}^{2}=0.996$

Figure 7. Average seed surface temperature $(\overline{S S T})$ and average air temperature $(\overline{A T})$ under different setpoint air temperature $(S A T)\left(12,16,20,24,28,32,36,40^{\circ} \mathrm{C}\right)$ and volumetric percentage of nutrient solution in seed tray (VPNS) of $86 \%$, each with 300 uncoated seeds (U) and coated seeds (C). Some data of $\overline{A T}$ include the average temperature of a shorter time period than $48 \mathrm{~h}$.

Table 3. Average air temperature $(\overline{A T})$, average germination time $(\overline{G T})$, average seed surface temperature $(\overline{S S T})$, germination percentage per 300 seeds $48 \mathrm{~h}$ after sowing $(G P)$, Identified percent, and coefficient of variation of germination time $(C V t)$ and seed surface temperature $(C V s)$ together with average hourly germination rate per 300 seeds $(\overline{G R})$, each with different volumetric percentage of nutrient solution in seed tray (VPNS), setpoint air temperature $(S A T)$, and uncoated seed (U)/coated seed (C). (see Table 1 for abbreviations).

\begin{tabular}{|c|c|c|c|c|c|c|c|c|c|c|}
\hline \multirow[b]{2}{*}{$\begin{array}{l}\text { Seed } \\
\text { Type }\end{array}$} & \multirow[b]{2}{*}{$\begin{array}{c}V P N S \\
(\%)\end{array}$} & \multirow[b]{2}{*}{$\begin{array}{l}S A T \\
\left({ }^{\circ} \mathrm{C}\right)\end{array}$} & \multicolumn{5}{|c|}{ Measured Value } & \multicolumn{3}{|c|}{ Calculated Value } \\
\hline & & & $\begin{array}{l}\overline{A T}^{1} \\
\left({ }^{\circ} \mathrm{C}\right)\end{array}$ & $\begin{array}{l}\overline{G T} \\
\text { (h) }\end{array}$ & $\begin{array}{l}\overline{S S T} \\
\left({ }^{\circ} \mathrm{C}\right)\end{array}$ & $\begin{array}{l}G P \\
(\%)\end{array}$ & $\begin{array}{c}\text { Identified } \\
\text { Percent }^{2} \\
(\%)\end{array}$ & $\begin{array}{c}C V t \\
{[S t / G T]}\end{array}$ & $\underset{[S t / S S T]}{C V s}$ & $\begin{array}{c}\overline{G R} \\
{[G P / \overline{G T}]} \\
\left(\% \mathrm{~h}^{-1}\right)\end{array}$ \\
\hline \multirow{10}{*}{$\mathbf{U}$} & \multirow{8}{*}{86} & 40 & 39.4 & 25.0 & 33.3 & 0 & - & - & 0.04 & 0.00 \\
\hline & & 36 & 35.9 & 21.8 & 30.3 & 1 & 67 & 0.2 & 0.02 & 0.05 \\
\hline & & 32 & 31.9 & 24.9 & 30.2 & 81 & 98 & 0.2 & 0.01 & 3.25 \\
\hline & & 28 & 27.9 & 21.7 & 25.9 & 100 & 83 & 0.3 & 0.01 & 4.60 \\
\hline & & 24 & 24.0 & 18.6 & 22.5 & 100 & 77 & 0.3 & 0.01 & 5.38 \\
\hline & & 20 & 20.4 & 27.2 & 18.9 & 100 & 90 & 0.2 & 0.01 & 3.68 \\
\hline & & 16 & 16.4 & 29.7 & 14.7 & 100 & 79 & 0.2 & 0.01 & 3.36 \\
\hline & & 12 & 12.9 & 38.2 & 10.4 & 100 & 46 & 0.1 & 0.02 & 2.62 \\
\hline & 82 & 20 & 19.9 & 23.6 & 19.4 & 100 & 86 & 0.2 & 0.00 & 4.23 \\
\hline & 77 & 20 & 20.0 & 26.7 & 20.4 & 100 & 89 & 0.2 & 0.01 & 3.74 \\
\hline \multirow{10}{*}{ C } & \multirow{8}{*}{86} & 40 & 38.3 & 22.8 & 32.2 & 91 & 62 & 0.3 & 0.03 & 3.98 \\
\hline & & 36 & 35.2 & 25.6 & 30.0 & 86 & 83 & 0.3 & 0.01 & 3.36 \\
\hline & & 32 & 31.9 & 24.3 & 28.7 & 79 & 97 & 0.4 & 0.01 & 3.24 \\
\hline & & 28 & 27.9 & 20.2 & 26.8 & 99 & 95 & 0.4 & 0.01 & 4.93 \\
\hline & & 24 & 25.8 & 29.2 & 23.8 & 100 & 99 & 0.2 & 0.00 & 3.42 \\
\hline & & 20 & 20.4 & 28.5 & 19.1 & 100 & 86 & 0.2 & 0.00 & 3.51 \\
\hline & & 16 & 16.4 & 33.0 & 15.6 & 100 & 81 & 0.2 & 0.01 & 3.02 \\
\hline & & 12 & 12.3 & 41.1 & 10.4 & 100 & 47 & 0.1 & 0.02 & 2.43 \\
\hline & 82 & 20 & 19.9 & 33.4 & 18.9 & 100 & 42 & 0.2 & 0.01 & 3.00 \\
\hline & 77 & 20 & 19.9 & 36.5 & 18.7 & 48 & 83 & 0.1 & 0.01 & 1.32 \\
\hline
\end{tabular}

1 Some data of $\overline{A T}$ include the average temperature of shorter time period than $48 \mathrm{~h} .{ }^{2}$ Identified percent: percentage of identified GT from red-green-blue (RGB) images per germinated seeds 48 HAS. 


\section{Discussion}

The objective of this study was to develop a plant phenotype measurement system to assess GT of individual seeds using time series data of 2D camera images and to analyze each GT as affected by its surrounding microenvironment and management factors of individual seeds for a wider plant cohort research project using the developed system. Experiments on germination were conducted to demonstrate the performance of the plant phenotype measurement system and its applicability for a whole plant growth process in a PFAL for large-scale commercial production and/or breeding.

Through the germination experiments of (1) different SAT with fixed VPNS and (2) different VPNS with fixed $S A T$ each with $U$ and $C, G T$ of individual seeds were obtained from RGB images and were assessed for the effect of its surrounding microenvironment (SST, VPNS, and air temperature) and management factors ( $\mathrm{U}$ and C) (Table 2). Our results together demonstrate the utility of the developed phenotyping unit for plant cohort research and future applications for further plant growth processes in PFAL for commercial production and/or breeding.

Traditional measurement of germination has been limited to the germination percentage of a seed population but not the germination time of individual seeds [17]. The result values of GP or $\overline{G T}$ shown in Table 3 represent an example of a previous germination measurement. Moreover, how microenvironment and management factors affect germination time of individual seeds and further plant growth had not been discussed in detail.

In this study, GT of individual seed could be obtained from time series data of 2D camera images, which were sent automatically and stored in the DWH together with other time course data captured from phenotyping and microenvironmental sensing units installed in GCB. Figure 6 illustrates GT of individual seeds sown in a seed tray each with 300 seeds under different treatments. Variance or uniformity of GT per 300 seeds was also demonstrated based on individual GT (Figure 5).

The results indicated that individual GT variations were affected by each microenvironment (SST, VPNS, and air temperature) and management factor such as seed type (U and C) (Figure 5, Figure 6). Each treatment with different air temperature or volumetric water/nutrient percent of the substrate, both with $U$ and C, reflected the differing tendency of $G T$ or variance of $G T$. In addition to microenvironmental factors, the results indicated that management factor (U and C) affected GT; GT itself and variance of GT varied in response to seed type (Figure 5, Figure 6).

Furthermore, this experiments showed differing $G P$, particularly $S A T$ of $36^{\circ} \mathrm{C}$ and $40^{\circ} \mathrm{C}$, between $\mathrm{U}$ and $\mathrm{C}$; little or no germination occurred with $\mathrm{U}$, whereas $G P$ with $\mathrm{C}$ and $S A T$ of $36^{\circ} \mathrm{C}$ and $40{ }^{\circ} \mathrm{C}$ were $86 \%$ and $91 \%$, respectively (Table 3). This result indicates that $C$ was less affected by microenvironment of higher air temperature. While on the other hand, with smaller volumetric percent in nutrient solution (VPNS), especially at $77 \%$ with $S A T$ of $20^{\circ} \mathrm{C}$, values of $\overline{G T}, \mathrm{GP}$, and $\overline{G R}$ were all smaller with $\mathrm{C}$ than $\mathrm{U}$ (Table 3). This implies that $\mathrm{C}$ was more affected by microenvironment of smaller volumetric water/nutrient percent of the substrate.

Figure 7 and Table 3 explained that under higher SAT, especially at $36^{\circ} \mathrm{C}$ and $40{ }^{\circ} \mathrm{C}, \overline{S S T}$ was lower than the SAT by approximately 6 to $8^{\circ} \mathrm{C}$, whereas $\overline{A T}$ remained closer to $S A T$ (even at higher $S A T)$. This implies that it is critical to observe the microenvironment, and more attention should be paid to analyzing the relationship between various factors of microenvironment, management, and dynamic phenotypes.

As Figure 6 demonstrated individual GT under different microenvironments of SST, VPNS and air temperature together with management factors of $U$ and $C$, it is presumed that some outliers of individual seeds can be found. Therefore, time series data of its surrounding microenvironment, management factors, and possibly genotype can be used to analyze what has generated the particular outliers [2]. Such analysis will also help to identify the causes of variation in seed germination time, which enables to remove the particular causes of variation [2].

We acknowledge that there are several limitations in this study. First, there were indeed limitations to determine GT from time series data of 2D camera images that were used for this study. By comparing with ground truth data on germination 48 HAS, GT of some germinated seeds were not obtained from 
the RGB images as shown with identified percent in Table 3. This challenge will be addressed in the future studies by improving the phenotyping unit and incorporating artificial intelligence (AI) in the system for automated acquisition of GT.

Second, there is a possibility that the result was affected by additional microenvironment and management factors other than SST, VPNS, air temperature, and seed type. In particular, inclination of water surface, which was possibly caused by procedures for manually carrying the seed tray or soaking substrate in the water/nutrient solution, may have caused variation or 2D horizontal distribution of SST. For the future study, 2D horizontal distribution should be taken into account to analyze the effect of microenvironment and management factors. The 2D horizontal distribution of individual phenotype, microenvironment and management, such as water/nutrient solution, light, substrate, and other factors, may occur particularly with further plant growth [2].

Third, seed lots used for this study were different for each seed type of $U$ and $C$. Ideally, the same seed population/lot should be used to compare the effect of management factor. In the future study, with the breeding and seed production in PFAL, this issue should be overcome by also tracing the seed production process and treatments.

In this study, the developed plant phenotype measurement platform revealed the effects of microenvironment and management factors on GT of individual seeds for plant cohort research. This indicates possibility of contributing to increasing in growth rate, plant quality and uniformity in plant production. In the future studies, additional conditions with multiple varieties/genotypes will be tested with this system. For the plant cohort research in PFALs, further study on plant growth stage is expected to continuously analyze individual phenotypes together with plant communities to assess interactions of plant phenotype dynamics with microenvironment, management, and genotype for life cycle history of individual plants to improve productivity of plant production and breeding in PFALs.

\section{Conclusions}

In this study, plant phenotype measurement system was developed to assess GT of individual seeds, using time-series 2D camera images, and to analyze how microenvironment and management factors affect the GT for plant cohort research. In particular, the low cost and compact modular system designed in this study emphasizes the practicality and scalability in commercial plant production in PFALs. Using this system, germination experiments were conducted to demonstrate the performance of the system and its applicability for a whole plant growth process in a PFAL for commercial production and/or breeding.

Through this study, GT of individual seeds were obtained from time series 2D camera images by using the developed modular plant phenotype measurement system as an initial stage of the plant cohort research in PFALs. Furthermore, the phenotyping platform revealed the effects of microenvironment and management factors on GT of individual seeds. Our modular plant phenotype measurement system should advance the commercial plant production in PFALs.

\section{Patents}

Chiba University; Japan Plant Factory Association. Plant cohort phenotyping system in plant factories with artificial lighting (PFALs) (in Japanese). No. 2019-027079, 19 February 2019.

Author Contributions: Conceptualization, T.K. and E.H.; methodology, T.K., E.H. and Y.A.; validation, E.H., Y.A. and T.M.; formal analysis, E.H., Y.A. and T.M.; investigation, Y.A.; data curation, Y.A.; writing-original draft preparation, E.H.; writing-review and editing, E.H. and Y.A.; visualization, E.H. and Y.A.; supervision, T.K. and E.H.; project administration, E.H.; funding acquisition, E.H. All authors have read and agreed to the published version of the manuscript.

Funding: This research was mainly funded by the New Energy and Industrial Technology Development Organization, No. JPNP15009, artificial intelligence (AI)-based plant phenomics in plant factories with artificial lighting (PFALs). 
Acknowledgments: The authors express their deep appreciation to Tomomi Nozaki, Osamu Nunomura, Yoshiko Komaba, Alex Williams Ayarna, Rikuo Hasegawa, Alex Feldman, Wei Guo, Yue Mu, Shinichi Saito, Mitsunori Abe, Yoshikazu Tsutsui, Hiroshi Tomoda, Takeshi Nagami and Takeshi Masuda for their technical support for the system development and experiments. The authors also thank to Daisuke Urano for critical reading and helpful comments on the manuscript.

Conflicts of Interest: The authors declare no conflict of interest.

\section{References}

1. Kumar, J.; Pratap, A.; Kumar, S. Phenomics in Crop Plants: Trends, Options and Limitations; Springer: New Delhi, India, 2015; p. 296.

2. Kozai, T.; Lu, N.; Hasegawa, R.; Nunomura, O.; Nozaki, T.; Amagai, Y. Plant Cohort Research and Its Application. In Smart Plant Factory: The Next Generation Indoor Vertical Farms; Kozai, T., Ed.; Springer: Berlin, Germany, 2018; pp. 413-432.

3. Fiorani, F.; Schurr, U. Future Scenarios for Plant Phenotyping. Annu. Rev. Plant Biol. 2013, 64, $267-291$. [CrossRef] [PubMed]

4. Golbach, F.; Kootstra, G.; Damjanovic, S.; Otten, G.; Van de Zedde, R. Validation of plant part measurements using a 3D reconstruction method suitable for high-throughput seedling phenotyping. Mach. Vis. Appl. 2016, 27, 663-680. [CrossRef]

5. Kuijken, R.C.; van Eeuwijk, F.A.; Marcelis, L.F.; Bouwmeester, H.J. Root phenotyping: From component trait in the lab to breeding. J Exp Bot. 2015, 66, 5389-5401. [CrossRef] [PubMed]

6. Guo, W. Automated Characterization of Plant Growth and Flowering Dynamics Using RGB images. In Smart Plant Factory: The Next Generation Indoor Vertical Farms; Kozai, T., Ed.; Springer: Berlin, Germany, 2018; pp. 385-393.

7. Ninomiya, S.; Baret, F.; Cheng, Z.-M. Plant phenomics: Emerging transdisciplinary science. Plant Phenomics 2019, 2019, 2765120. [CrossRef]

8. Goto, E. Plant production in a closed plant factory with artificial lighting. Acta Hortic. 2012, 956, 37-49. [CrossRef]

9. Kozai, T. Resource use efficiency of closed plant production system with artificial light: Concept, estimation and application to plant factory. Proc. Jpn. Acad. Ser. B Phys. Biol. Sci. 2013, 89, 447-461. [CrossRef] [PubMed]

10. Leong, R.; Urano, D. Molecular Breeding for Plant Factory: Strategies and technology. In Smart Plant Factory: The Next Generation Indoor Vertical Farms; Kozai, T., Ed.; Springer: Berlin, Germany, 2018; pp. 301-323.

11. Kozai, T.; Amagai, Y.; Hayashi, E. Towards sustainable plant factories with artificial lighting (PFALs): From greenhouses to vertical farms. In Achieving Sustainable Greenhouse Cultivation; Marcelis, L., Heuvelink, E., Eds.; Burleigh Dodds Science Publishing: Cambridge, UK, 2019; pp. 177-204.

12. Kozai, T.; Hayashi, E.; Amagai, Y. Plant factories with artificial lighting (PFALs) toward sustainable plant production. Acta Hortic. 2020, 1273, 251-260. [CrossRef]

13. Ohyama, K.; Yamaguchi, J.; Enjoji, A. Resource Utilization Efficiencies in a Closed System with Artificial Lighting during Continuous Lettuce Production. Agronomy 2020, 10, 723. [CrossRef]

14. SharathKumar, M.; Heuvelink, E.; Marcelis, L.F.M. Vertical Farming: Moving from Genetic to Environmental Modification. Trends Plant Sci. 2020, 25, 724-727. [CrossRef] [PubMed]

15. Nagano, S.; Moriyuki, S.; Wakamori, K.; Mineno, H.; Fukuda, H. Leaf-Movement-Based Growth Prediction Model Using Optical Flow Analysis and Machine Learning in Plant Factory. Front. Plant Sci. 2019, 10, 227. [CrossRef] [PubMed]

16. Soltani, E.; Ghaderi-Far, F.; Baskin, C.C.; Baskin, J.M. Problems with using mean germination time to calculate rate of seed germination. Aust. J. Bot. 2015, 63. [CrossRef]

17. Bewley, J.D.; Bradford, K.J.; Hilhorst, H.W.M.; Nonogaki, H. Seeds: Physiology of Development, Germination and Dormancy, 3rd ed.; Springer: New York, NY, USA, 2013; p. 392.

18. Baskin, C.C.; Baskin, J.M. Seeds: Ecology, Biogeography, and Evolution of Dormancy and Germination, 2nd ed.; Elsevier/Academic Press: San Diego, CA, USA, 2014; p. 1586.

19. Gustin, J.L.; Settles, A.M. Seed Phenomics. In Phenomics: How Next-Generation Phenotyping is Revolutionizing Plant Breeding; Fritsche-Neto., R., Borém, A., Eds.; Springer: Cham, Switzerland, 2015; pp. 67-82. 
20. Ducournau, S.; Feutry, A.; Plainchault, P.; Revollon, P.; Vigouroux, B.; Wagner, M.H. Using computer vision to monitor germination time course of sunflower (Helianthus annuus L.) seeds. Seed Sci. Technol. 2005, 33, 329-340. [CrossRef]

21. Shinohara, T. Seed Vigour as a New Seed Quality lndex and lts Utility. Jpn. Soc. Agric. Technol. Manag. 2009, 16,1-9. (In Japanese)

22. Joosen, R.V.; Kodde, J.; Willems, L.A.; Ligterink, W.; van der Plas, L.H.; Hilhorst, H.W. GERMINATOR: A software package for high-throughput scoring and curve fitting of Arabidopsis seed germination. Plant J. 2010, 62, 148-159. [CrossRef] [PubMed]

23. Ligterink, W.; Hilhorst, H.W.M. High-Throughput Scoring of Seed Germination. In Plant Hormones; Kleine-Vehn, J., Sauer, M., Eds.; Humana Press: New York, NY, USA, 2017; Volume 1497, pp. 57-72. [CrossRef]

24. Hayashi, E.; Kozai, T. Phenotyping and AI-based Environmental Control and Breeding for PFAL. In Smart Plant Factory: The Next Generation Indoor Vertical Farms; Kozai, T., Ed.; Springer: Berlin, Germany, 2018; pp. 405-411.

25. Hasegawa, R. Data warehouse for plant phenotyping in plant factories. In Proceedings of the Meeting of Japanese Society of Agricultural, Biological and Environmental Engineers and Scientists (JSABEES), Tokyo, Japan, 18-21 September 2018; pp. 224-225.

26. R Core Team. R: A Language and Environment for Statistical Computing. R Foundation for Statistical Computing:Vienna, Austria, 2019. Available online: https://www.r-project.org/ (accessed on 8 August 2020).

27. International Seed Testing Association (ISTA). International Rules for Seed Testing. International Seed Testing Association: Zurich, Switzerland, 2019. Available online: https://www.seedtest.org/en/internationalrules-for-seed-testing-_content---1--1083 (accessed on 17 April 2020).

28. Maruo, T.; Ito, T.; Ishii, S. Studies on the feasible management of nutrient solution in hydroponically growth lettuce (Lactuca sativa L.). Tech. Bull. Fac. Hort. Chiba Univ 1992, 46, 235-240.

Publisher's Note: MDPI stays neutral with regard to jurisdictional claims in published maps and institutional affiliations.

(C) 2020 by the authors. Licensee MDPI, Basel, Switzerland. This article is an open access article distributed under the terms and conditions of the Creative Commons Attribution (CC BY) license (http://creativecommons.org/licenses/by/4.0/). 